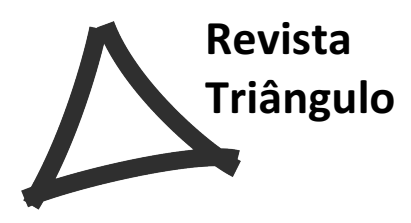

\title{
UMA PRÁTICA DE ENSINO DE LÍNGUA PORTUGUESA: A SEQUÊNCIA DIDÁTICA
}

\author{
THE PRACTICE OF PORTUGUESE LANGUAGE TEACHING: DIDACTIC \\ SEQUENCE
}

\author{
Odília Olinda de Oliveira Vieira ${ }^{1}$ \\ Marinalva Vieira Barbosa ${ }^{2}$
}

\begin{abstract}
RESUMO
Este trabalho tem como finalidade apresentar uma experiência vivenciada com uma proposta de ensino de Língua Portuguesa, a sequência didática. Inicialmente, foi situada a importância do texto como a base de ensino de língua. O primeiro momento foi situar a persistência da gramática normativa em sala de aula. Em contrapartida, aparece a proposta de Geraldi, adotando a Análise Linguística como estratégia educacional, totalmente voltada para a leitura do texto e para a produção textual do aluno. Mendonça assume essa proposta, criando uma sequência didática como opção de estudo da língua no Ensino Médio. Para uma melhor compreensão do assunto, houve uma retomada da sequência didática criada por Dolz, Noverraz e Scheneuwly e depois, uma comparação da proposta brasileira com a dos autores. Na fase final do trabalho, foram analisadas produções de alunos de ensino Fundamental II e alguns obstáculos que não possibilitaram um bom andamento das atividades, comprometendo, em parte, os resultados. Esta Atividade foi proposta pelo conteúdo "Texto e Ensino".
\end{abstract}

Palavras-chave: Texto. Ensino. Sequência.

\begin{abstract}
This work has the goal to expose a lived experience with a Portuguese Language teaching proposal, the didactic sequence. At the beginning, it was figured out the text importance as the base of language teaching. The first moment was lined the normative grammar persistence at classroom. In the other hand, the Geraldi's proposal appears using the Linguistic Analysis how educational strategy, it directed totally to the reading of the text and the student's textual production. Mendonça adopts that proposal creating a didactic sequence as an option of high school language researching. For a better subject comprehension there has been returning the didactic sequence created by Dolz, Noverraz and Scheneuwly with the later comparison between the Brazilian proposal and that from the authors. At the work's final stage, it was analyzed the students' productions from high school II and some barriers that have not made possible an good activity development, what in part bring some damage to the results. This activity was proposed by the content "Text and Teaching".
\end{abstract}

Keywords: Text. Teaching. Sequence.

\footnotetext{
${ }^{1}$ Universidade Federal do Triângulo Mineiro - UFTM. Email: ooovieira@yahoo.com.br

${ }^{2}$ Universidade Federal do Triângulo Mineiro - UFTM. Email: marinalvav@gmail.com
} 


\section{Introdução}

O ensino de Língua Portuguesa, ao longo do tempo, vem sofrendo alterações, adequando-se às novas pesquisas que exigem uma prática diferenciada. A própria mudança de concepção de língua que já foi tida como expressão do pensamento e instrumento de comunicação conduz a uma perspectiva de ensino distanciada da normatização rígida, inflexível, buscando uma visão discursiva da linguagem.

Hoje, a língua é concebida como um processo dinâmico que se constitui através das relações sociais e estabelece a significação no processo de interação, dialogicamente, num dado contexto. Inserida nessa concepção, a escola, para promover o desenvolvimento e a eficiência linguística do aluno, torna-se o espaço vivo de produção e recepção de textos.

O objetivo deste trabalho foi testar uma proposta de ensino em alunos do Ensino Fundamental II, a sequência didática, adotada por Mendonça $\left(2006\right.$, p.208) ${ }^{3}$ como prática de ensino de Língua Portuguesa no Ensino Médio. Essa proposta faz uma integração entre o estudo do texto com a produção textual do aluno. Através desta produção, faz-se um levantamento de problemas linguísticos que serão trabalhados durante as aulas, em substituição às tradicionais aulas de gramática normativa. Esse procedimento didático foi nomeado de Análise Linguística (doravante AL), servindo de suporte para estudo da língua. A finalização da sequência de atividades se dá com o retorno ao texto do aluno, após o estudo dos problemas elencados pelo professor para, em seguida, proceder a reescrita da produção inicial.

\section{Da normatização estrutural ao texto}

A gramática normativa ainda povoa as práticas escolares do ensino de Língua Portuguesa. Está havendo uma camuflagem delas, com alegação de que a aprendizagem linguística está contextualizada, mas a normatização vai se constituindo sem verificar em que condições de uso essas "normas" poderiam ser inseridas. Mesmo com toda renovação do livro didático, centrando o ensino nos gêneros textuais, o assunto gramática continua sendo neles uma prática distanciada das situações de uso.

\footnotetext{
3 -Bunzen, C. e Mendonça, M. (Org.) - Português no ensino médio e formação do professor. Parábola Editorial, 2006.
} 
O livro “O texto na sala de aula", organizado por Geraldi (1984 -2012) trouxe uma proposta renovadora, constituída por ele mesmo, para alterar o panorama da prática viciada da normatização. Inicialmente, o professor escolhe um texto curto para realizar um estudo detalhado e profundo dele, evitando a interpretação superficial e linear.

Todo esse trabalho vai servir de base para a produção textual do aluno que será avaliada pelo professor com o intuito de elencar alguns problemas a serem trabalhados com a turma. Esse procedimento foi nomeado de Análise Linguística, em substituição às aulas de gramática normativa. O autor alerta para duas coisas: deve-se desenvolver um assunto de cada vez e não se trata de deixar de ensinar a gramática da língua.

A finalização dessas atividades se dá com o retorno ao texto do aluno para proceder a sua reescrita, objetivo principal da AL, como o próprio Geraldi afirma:

Essencialmente, a prática da análise linguística não poderá limitar-se a higienização do texto do aluno, em seus aspectos gramaticais e ortográficos, limitando-se a "correções". Trata-se de trabalhar com o aluno o seu texto para que ele atinja seus objetivos junto aos leitores a que se destina. (2012, p. $74)^{4}$.

É importante ressaltar aqui que esse trabalho pode ser feito de diferentes formas, atraindo e mobilizando o interesse do aluno. O que não pode é transformar a prática de $\mathrm{AL}$ em aula de gramática normativa, mas como "práticas sociais significativas e integradas". O texto será sempre o ponto de partida e o ponto de retorno para o ensino da língua.

Mendonça (2006, p.208) $)^{5}$ adotou a AL e desenvolveu uma sequência didática como suporte das aulas de Língua Portuguesa. A AL inclui a norma de prestígio, mas vai além:

O que configura um trabalho de AL é a reflexão recorrente e organizada, voltada para a produção de sentidos e/ou para a compreensão mais ampla dos usos e do sistema linguísticos, com o fim de contribuir para a formação de leitores-escritores de gêneros diversos, aptos a participarem de eventos de letramento com autonomia e eficiência.

\footnotetext{
4 -Geraldi, J. W. O texto na sala de aula. Martins Fontes, 2012. P. 74.

5 - -Buzen, C. e Mendonça, M. (orgs) - Português no ensino médio e formação do professor. Parábola Editorial, 2006.
} 


\section{Uma proposta de ensino: a sequência didática}

Naturalmente, o falante da língua já traz em si uma competência para diferenciar textos que compõem o seu cotidiano, mesmo que ele o faça de forma espontânea, destituído de base teórica, pois são reveladores das práticas sociais.

O texto, em sala de aula, intensifica o contato do aluno com elementos linguísticos de diversas ordens, contextualizados, que já passaram por uma seleção dentre os recursos infinitos que a língua possibilita aos seus usuários, não só na produção de sentidos, como também na forma de alicerçar a própria interação como prática sociocultural. $\mathrm{O}$ aluno, em contato com uma prática de linguagem já situada e com a perspectiva de se tornar sujeito do processo interativo, passa a conceber a língua como uma força que lhe garantirá sua inserção num contexto, possibilitando-lhe um trânsito mais eficiente nas diferentes esferas sociais. Segundo Geraldi (2013, p.122) ${ }^{6}$, o ensino da língua sairia do reconhecimento e reprodução para o ensino do conhecimento e produção.

A proposta deste trabalho foi colocar em prática essa perspectiva de ensino da língua, vivenciando uma sequência didática (doravante SD), com uma turma de $9^{\circ}$ ano de uma escola pública.

A SD foi proposta por Dolz, Noverraz e Schneuwly (2004, tr. de ROJO e CORDEIRO) ${ }^{7}$. De acordo com os autores, é necessário que a escola possibilite a prática de produção textual e a expressão oral em situações públicas escolares e extraescolares: "Uma proposta como essa tem sentido quando se inscreve num ambiente escolar no qual múltiplas ocasiões de escrita e de fala são oferecidas aos alunos, sem que cada produção se transforme, necessariamente, num objeto de ensino sistemático.” (Idem, p.96).

A SD proposta por eles constitui-se de atividades escolares organizadas, de maneira sistemática, centradas num gênero textual oral ou escrito. Os gêneros textuais apresentam uma certa regularidade de construção, pois estão inseridos em uma prática social. Deixam evidentemente claro que nem todos precisam ser contemplados na prática escolar, há necessidade de se fazer uma seleção deles para compor o trabalho na escola. O enfoque se volta para as práticas de linguagem novas ou de difícil domínio. $\mathrm{Na}$ verdade, a escola não deve repetir aquilo que o aluno já domina e sim, promover o crescimento linguístico dele.

\footnotetext{
6 - Geraldi, J. W. Portos de passagem. Martins Fontes, 2013.

7 -Scheneuwly, B. e Dolz, J. (tr. De Rojo, R.e Cordeiro, G. S.) - Gêneros orais e escritos na escola. Editora Cortez, 2004.
} 
Essa SD possui uma estrutura de funcionamento que se divide em: apresentação da situação de produção, texto inicial, módulos e produção final.

$\mathrm{Na}$ apresentação da situação - nessa fase inicial, há a proposta do que será trabalhado, podendo ter como ponto de partida a leitura de um texto similar ou uma explicação detalhada sobre o gênero proposto. Explicita o destinatário, a forma de representação (divulgação), quem são os envolvidos na produção. $O$ professor pode trabalhar com a produção oral (gravando) ou escrita (contemplando as duas modalidades). É um momento intenso de leitura, debates, pesquisa, se for o caso. Eles evidenciam que, devido a extensão do trabalho, duração e envolvimento, a SD deve ser concebida como um projeto de classe, numa situação definida.

Finalizada a fase preparatória, os alunos são submetidos à produção inicial. Passa depois pelo olhar clínico do professor para diagnosticar os seus problemas, os ajustes necessários, as dificuldades apresentadas, quais exercícios serão trabalhados. Essa produção direciona o trabalho a ser feito para resolver ou minimizar as dificuldades dos alunos, portanto ela tem caráter formativo e não avaliativo. Os alunos têm uma participação direta nos debates, estudos e sugestões; juntamente com o professor, estabelecem uma linguagem comum, adequada à produção e definem com precisão as limitações da turma.

Tendo em mãos todos os problemas e os procedimentos a seguir, inicia-se a fase dos módulos que vão dar o suporte teórico e prático para sanar as dificuldades. É relevante ressaltar aqui que o alvo principal não são diretamente os problemas linguísticos, mas especialmente os recursos ligados à produção do gênero em questão. Os problemas específicos da língua terão aulas separadas para resolvê-los.

Para que haja um trabalho consistente na produção feita, eles estabelecem alguns níveis direcionadores do trabalho:

i- representação de uma situação de comunicação : idealizar destinatário, a constituição do aluno como autor ou locutor e o gênero desejado;

ii- elaboração dos conteúdos: aprender técnicas de elaboração do conteúdo;

iii- planejamento do texto: montar o plano, a finalidade proposta ou ao destinatário;

iv- realização do texto: escolhas linguísticas, adequação de tempos verbais e escolhas dos organizadores textuais.

A fase de módulos deve ser rica em atividades diversas e exercícios para que os alunos treinem para resolver os próprios problemas. Em primeiro lugar, eles realizam atividades de análise e observação de outros textos para relacioná-los, compará-los ou distingui-los. Depois fazem tarefas simplificadas de produção textual: inserir partes em um texto, revisar partes, 
refutar ou defender alguma argumentação, elaborar questões a partir de certas respostas. Finalizam com exercícios de elaboração linguística para adequar devidamente a linguagem a uma situação definida.

À medida que os alunos vão fazendo as atividades, vão registrando os conhecimentos adquiridos sobre o gênero ou criando lembretes para a fase final.

Esgotada a fase dos módulos, os alunos começam a produção final do texto, aplicando tudo o que aprenderam.

É importante destacar aqui que esse tipo de SD não tem a preocupação específica com o estudo da língua, se isso ocorre porque foi decorrente da necessidade de resolver problemas de adequação linguística ao gênero em questão. Tudo se direciona para a eficiência da produção textual proposta.

\section{A sequência didática no Brasil}

Hoje, a escola brasileira se volta para o estudo dos gêneros textuais. Tornou-se, praticamente, uma obrigatoriedade nos livros didáticos a sua presença, mas o ensino da língua continua sendo feito divorciado do que os textos realizam na construção dos significados. Geraldi $(2013, \text { p. } 105)^{8}$ evidencia que o ensino da língua deve sustentar-se no trabalho com o texto, na leitura e produção. A especificidade da aula de português se estabelece com o trabalho textual. E, para fugir da prática puramente metalinguística, propõe a AL como estratégia de ensino da língua, decorrente dos estudos e das produções textuais dos alunos. $\mathrm{O}$ professor analisa as produções e prioriza o que foi problemático para fazer um estudo com a sala de aula, usando estratégias contextualizadas. Após o estudo, os textos são reescritos pelos alunos. Para ele, saber a língua é:"Dominar habilidades de uso da língua em situações concretas de interação, entendendo e produzindo enunciados, percebendo as diferenças entre uma forma de expressão e outra." (Idem, 2012, p.45 e 46) ${ }^{9}$.

Mendonça $\left(2006\right.$, p.200) ${ }^{10}$ retoma essa proposta e estabelece uma sequência de atividades didáticas para o ensino de língua portuguesa. Há semelhanças e diferenças na sua

\footnotetext{
8 - Geraldi, J. W. Portos de passagem. Martins Fontes, 2013.

9 - Geraldi, J. W. O texto na sala de aula. Martins Fontes, 2012.

10 - Buzen, C. e Mendonça, M. (orgs) - Português no ensino médio e formação do professor. Parábola Editorial, 2006.
} 
proposta com a de Dolz, Noverraz e Scheneuwly (2004) ${ }^{11}$, já descrita nesse trabalho. Para eles, a sequência tem seu início com uma apresentação minuciosa do gênero a ser desenvolvido. Mendonça parte de um estudo de texto como elemento sustentador e motivador da produção textual.

$\mathrm{Na}$ terceira fase da sequência, após a avaliação do professor, dividem os problemas surgidos em módulos, priorizando os componentes do gênero proposto, com uma vasta diversidade de recursos, inclusive vários textos similares. Os problemas linguísticos abordados são aqueles necessários a construção do gênero. A preocupação deles não é ensinar especificamente o uso da língua.

A proposta brasileira harmoniza os dois estudos, inclusive, há o destaque para o ensino da língua em situação específica de uso, como se vê nesta passagem: “a prática de AL estará relacionada aos demais eixos de ensino de língua materna, constituindo uma ferramenta para a potencialização das habilidades, de leitura e escrita conforme dizem os PCN de Língua Portuguesa do EFII (1998c: 34):

Ainda que a reflexão seja constitutiva de atividade discursiva, no espaço escolar reveste-se de maior importância, pois é na prática de reflexão sobre a língua e linguagem que pode se dar a construção de que permitirão ao sujeito o desenvolvimento da competência discursiva para falar, escutar, ler e escrever nas diversas situações de interação. (Mendonça, 2006 p. 209 e $210)^{12}$.

Após a produção, o professor seleciona caso ou casos relevantes na construção do texto e o uso linguístico inadequado. A partir daí, é feito um trabalho contextualizado, fundamentando o uso adequado para a situação, com exercícios de fixação. Finda a AL, os textos são devolvidos aos alunos para proceder a reescrita deles.

Essa proposta de ensino da língua possibilita ao aluno um domínio dos recursos linguísticos num contexto definido, com acesso a linguagem privilegiada, afastando-o da normatização improdutiva.

\section{Vivenciando a sequência didática}

\footnotetext{
11 - Scheneuwly, B. e Dolz, J. (tr. De Rojo, R.e Cordeiro, G. S.) - Gêneros orais e escritos na escola. Editora Cortez, 2004.

12 - Buzen, C. e Mendonça, M. (orgs) - Português no ensino médio e formação do professor. Parábola Editorial, 2006.
} 
A experiência com a sequência didática foi vivenciada com uma turma de $9^{\circ}$ ano do Ensino Fundamental de uma escola pública, adotando a proposta de Mendonça.

A definição de um texto para principiar o trabalho é muito importante, pois ele fundamenta o estudo linguístico e funciona como a base da produção textual do aluno. O texto apresenta um enunciador que, numa situação definida, atua discursivamente. Através dele, são percebidos os posicionamentos, as ações do enunciador por meio de estratégias linguísticas.

O texto escolhido foi um condensado do livro "Ciganos", de Bartolomeu Campos Queirós, uma narrativa literária que, em certos momentos, torna-se poética, com um farto trabalho linguístico. Ao interpretá-lo, o aluno necessitou perceber as estratégias linguísticas reveladoras de posicionamentos, sentimentos do enunciador e as reações dos moradores, como se vê na abertura do texto:

Como num sonho, denso e distraído, os ciganos montavam tendas em terreno vago, sempre perto do descampado da igreja, enquanto pelas frestas e janelas tantos olhos os vigiavam. Nascia assim, de repente como a morte, uma vila colorida que se aninhava naquele povoado antigo. A presença dos ciganos mudava o ritmo de ser da cidade. Portas eram cerradas, roupas não dormiam no varal, nem cavalos soltos nos pastos. (QUEIRÓS, 1982) (13 $^{13}$

Durante todo o estudo do texto, o aluno precisava fazer inferência, buscar a pressuposição para perceber os possíveis significados revelados pelas escolhas linguísticas do autor. No desenvolvimento do texto, sabe-se que os moradores estão presentes, mas não se revelam concretamente, é como se eles se anulassem, perdessem sua identidade com a presença dos ciganos, como nesta passagem: "E nas mãos que a cidade oferecia, estas ciganas - tiradoras de sorte - liam futuros cheios de amor e fortuna."

Para que o aluno pudesse interpretar, perceber essas construções linguísticas, foram elaboradas questões oferecendo pistas para possíveis leituras que eram complementadas com comentários e permutas de respostas fornecidas por eles. A riqueza do trabalho se deu mais pela análise oral do que escrita. Finalizando a parte do estudo do texto, foi feita uma conclusão com destaque para as construções linguísticas e os efeitos de sentido produzidos por elas.

A não possibilidade de fazer um trabalho contínuo acabou comprometendo, em parte, os resultados das etapas subsequentes. Após uma semana, os alunos foram submetidos à produção textual. Foi necessária uma retomada dos recursos linguísticos, os efeitos de sentido

\footnotetext{
13 - Queirós, B. C. Ciganos.Global Editora. 1982.
} 
deles e, associado a isso, receberam algumas orientações sobre o gênero a ser produzido, a necessidade de se pensar num destinatário para o texto, com a ressalva de que, ao produzir um texto, o enunciador revela posicionamentos, intencionalidades, visão de vida, dependendo das escolhas linguísticas feitas por ele. Receberam quatro sugestões para produzir o texto, todas associadas ao assunto do texto estudado.

O procedimento seguinte foi a análise linguística do que os alunos conseguiram realizar em suas produções. Não houve uma correção sobre o texto, mas uma utilização de símbolos para que o próprio aluno reelaborasse o seu trabalho.

O processo subsequente foi centralizar os problemas mais comuns da turma para compor a prática de AL. A falta de estruturação dos textos, sequenciamento das ideias e a acentuação dos homógrafos apareceram em quase todos os textos. A decisão de trabalhar com os três assuntos ao mesmo tempo acabou prejudicando, além da escassez do tempo. Os alunos, praticamente, fixaram apenas um deles. Aqui confirma o que Geraldi $\left(2012\right.$, p.74) ${ }^{14}$ disse que "para cada aula de prática de análise linguística, o professor deverá selecionar apenas um problema. De nada adianta querermos enfrentar de uma vez todos os problemas que podem ocorrer num texto produzido por nosso aluno."

Para desenvolver essa etapa, os alunos receberam mais dois textos narrativos com discurso direto para perceberem bem a paragrafação e a estruturação, pois a maioria fez uso do discurso direto em suas produções. Um dos textos, inclusive, trabalhou com recursos linguísticos semelhantes ao de Bartolomeu. Foi feita uma análise verbal comparativa dos textos e a importância que a pontuação teve na significação de cada um. A acentuação dos homógrafos foi trabalhada em contexto bem definido, mostrando a significação de cada uma em partes dos textos já estudados. Para trabalhar a progressão das ideias, além dos textos indicados, foram destacadas três passagens de texto dos próprios alunos (com omissão dos nomes) para demonstrar o porquê não houve o desenvolvimento e o que fazer com as ideias apenas citadas e acumuladas em uma única estrutura.

\section{Resultados da vivência}

A experiência inicial já apontou para a necessidade de alguns ajustes que acabaram comprometendo a sua eficácia. Realizada dentro de uma estrutura favorável e mantendo o

\footnotetext{
14 - Geraldi, J. W. O texto na sala de aula. Martins Fontes, 2012.
} 
tempo suficiente para que cada etapa aconteça devidamente, é uma prática de ensino da língua que motiva o aluno, que o leva a refletir sobre a escolha de construções linguísticas adequadas a um contexto definido.

Como já foi dito acima que o professor deve escolher um problema de cada vez para ser trabalhado na AL, o melhor resultado centralizou no primeiro assunto desenvolvido com a turma: estruturação do texto narrativo. Interessante lembrar aqui que os problemas dos textos foram marcados com símbolos. Quando o aluno fez a reescrita, acabou mexendo com outras dificuldades que não tinham sido destacadas para o estudo do momento e conseguiram melhorar bem a sua produção.

Um fato chamou atenção durante a reescrita: muitos alunos corrigiram o que foi marcado pelos símbolos, mas acabaram provocando novos desvios onde, anteriormente, não havia. Com isso, percebe-se que há uma certa desatenção, quando escrevem. $\mathrm{O}$ aluno não tem a preocupação de reler o que acabou de escrever. Outros, realmente, tiveram dificuldade de entender os símbolos.

Os textos usados, visualizando os resultados obtidos, receberam uma enumeração no lugar dos nomes dos alunos.

O texto 1 apresentou, no início, uma certa incoerência com o uso dos marcadores temporais quando e já. A intencionalidade da aluna de causar o efeito surpresa, susto, não ficou bem constituída, principalmente, com a repetição do quando. Na reescrita, ela fez uma elaboração coerente e aí é interessante observar que, no seu rascunho (solicitou para fazer as correções no original), ajeitou a pontuação, colocou assustados com maiúscula e não o fez ao passar para a outra folha, confirmando o que foi dito acima. O texto não foi organizado em parágrafos. Ela não percebeu o símbolo indicador de parágrafos, manteve como estava. 
Texto 1

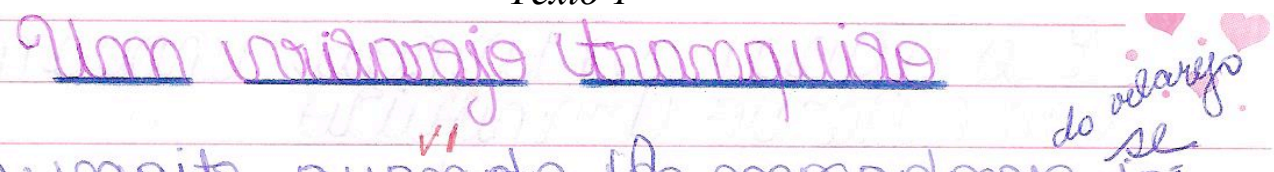

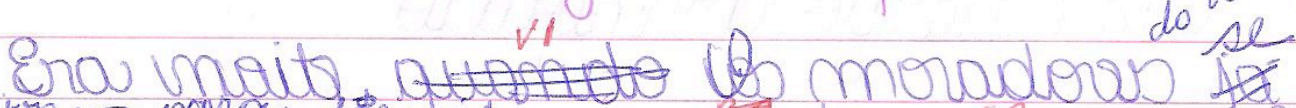

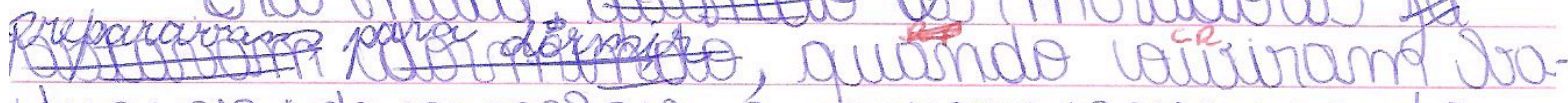

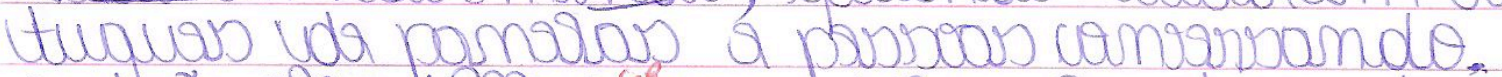

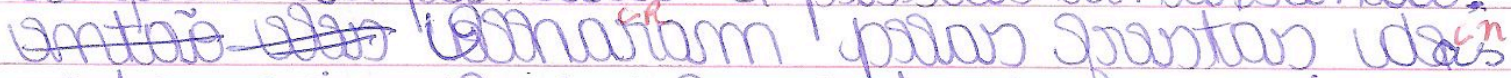

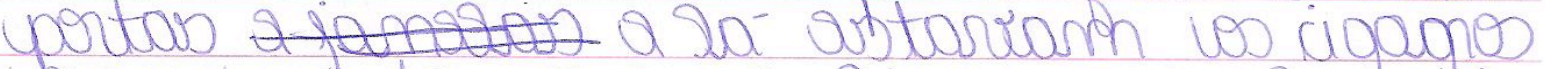

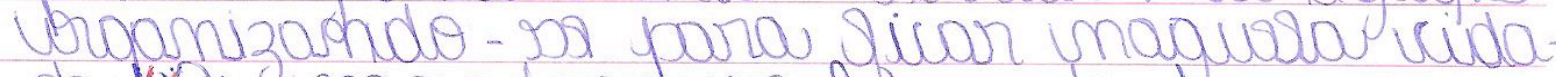

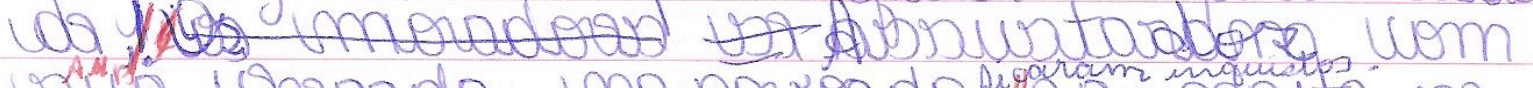

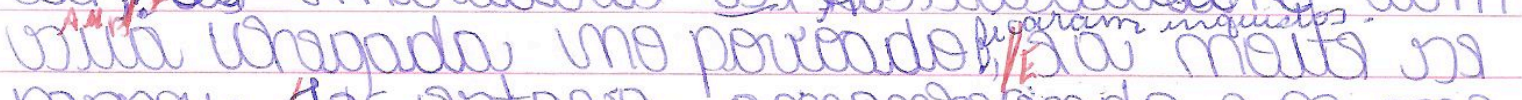

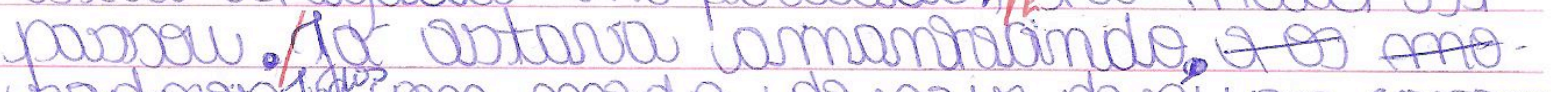

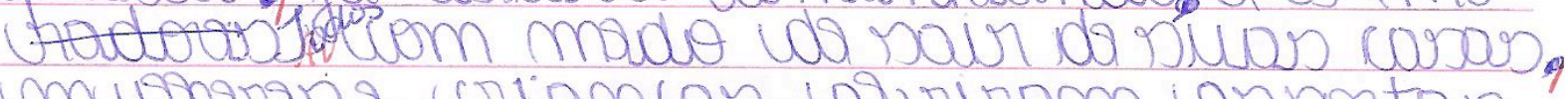

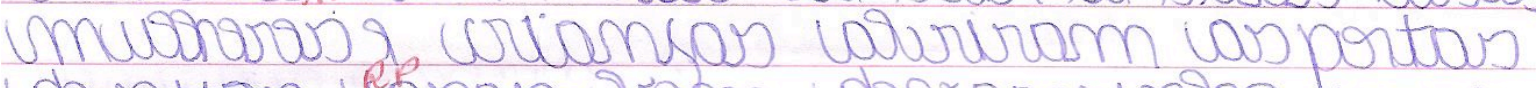

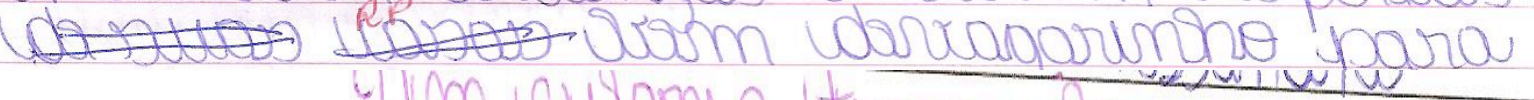
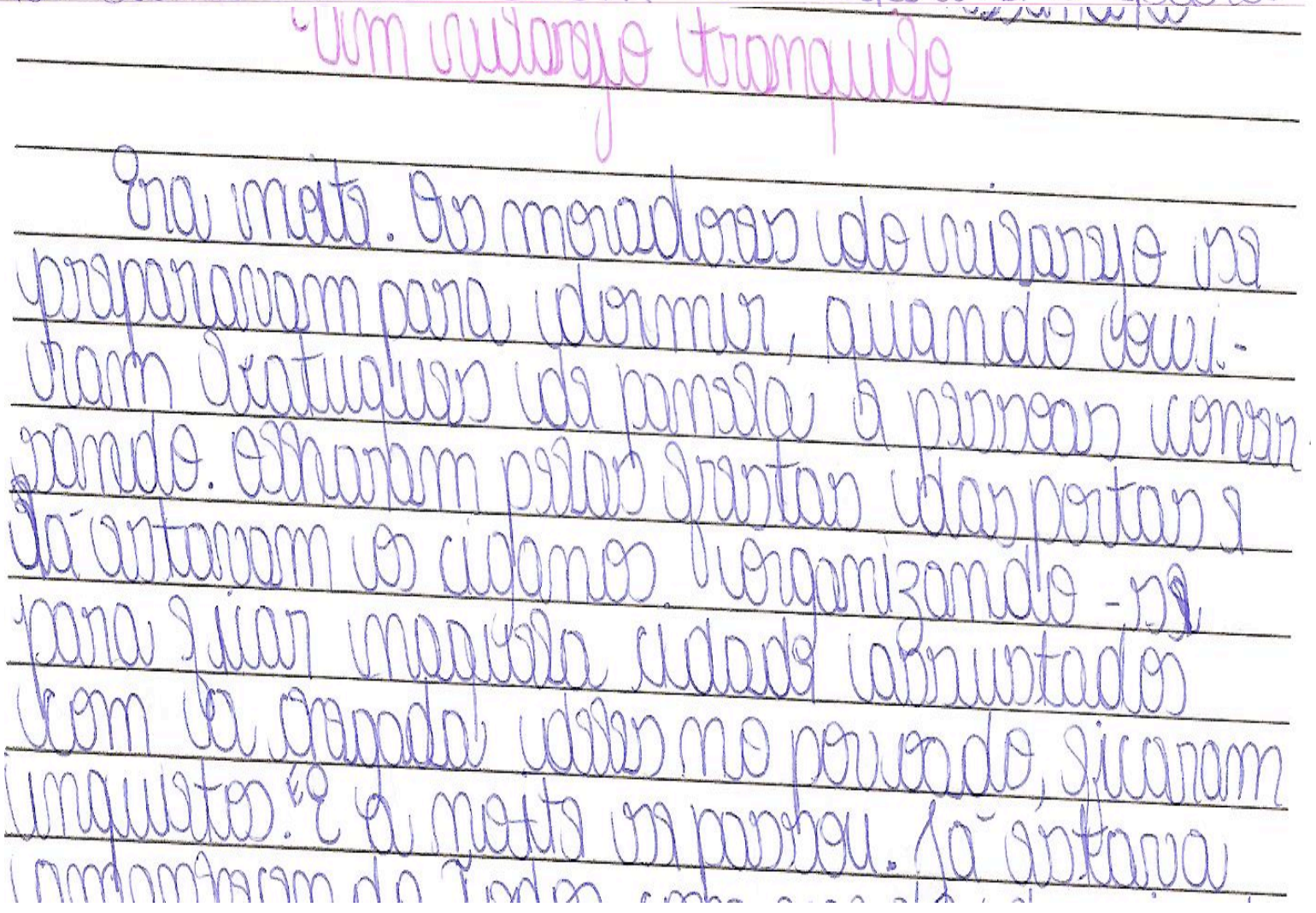

No texto 2, o aluno apresentou muita dificuldade na progressão das ideias. Percebe-se que ele tem, em alguns momentos, a noção de parágrafos e já marcou o fantástico, imaginário na abertura com Era uma vez. Na reescrita, melhorou um pouco a pontuação, clareou um pouco algumas ideias, mas nenhuma melhora na progressão. 
Texto 2

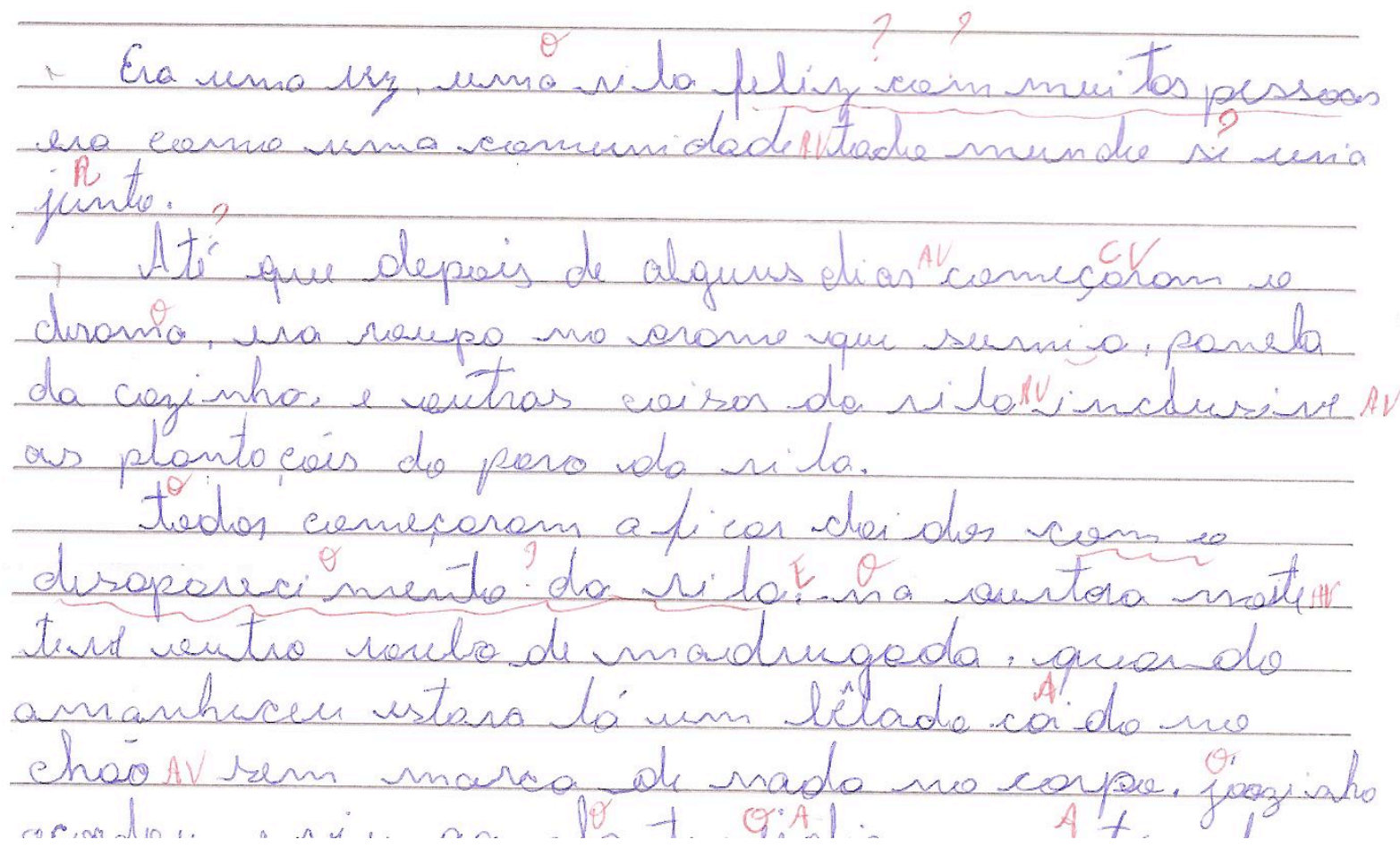

Erasuma very uma riba com unitas pesseos tippo unar camuni dady, tode unumde si unia junte. Até rque depieis de alguns dias, começare e drama ma Vila, ura reupa no crame que sumía, parrela da

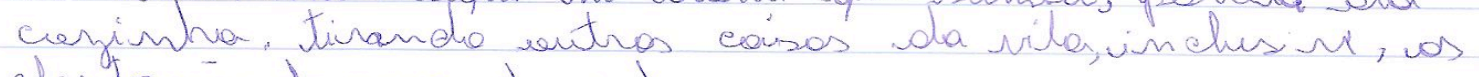
planto-cieies de pero do rilo.

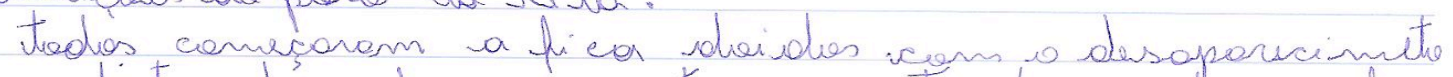

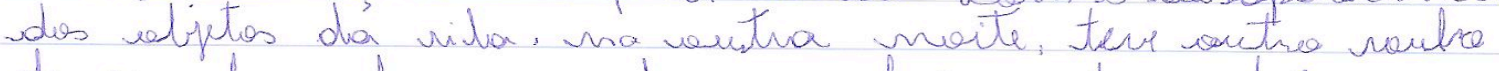
de madrugada. aquando amonhefer estara lá ium

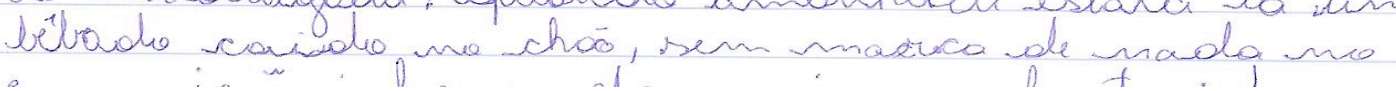

O texto 4 é um conto, bastante longo. Houve um esforço muito grande desse aluno, pois ele tinha a pretensão de utilizar recursos linguísticos semelhantes aos dois textos estudados (o texto inicial da sequência e o que foi utilizado na AL), principalmente, na constituição do personagem e na progressão textual. $O$ aluno conseguiu trabalhar com diferentes vozes no texto. Em dois momentos, na tentativa de criar mistério e clímax, realizou construções incoerentes, quando quis criar o mistério em torno da doença da cigana e suas visões. Estas não estavam bem delineadas. Apresentava-se sempre solitária nas visitas à aldeia e, de repente, ela aparece com seguidores. O texto apresentou também problemas na paragrafação e períodos muito longos. Em alguns momentos, houve misturas de situações que, se colocadas em parágrafos diferentes, favoreceriam mais a leitura. Na reescrita, os 
problemas, praticamente, foram resolvidos, menos os períodos longos. Foi o aluno com melhor aproveitamento das atividades realizadas durante a SD.

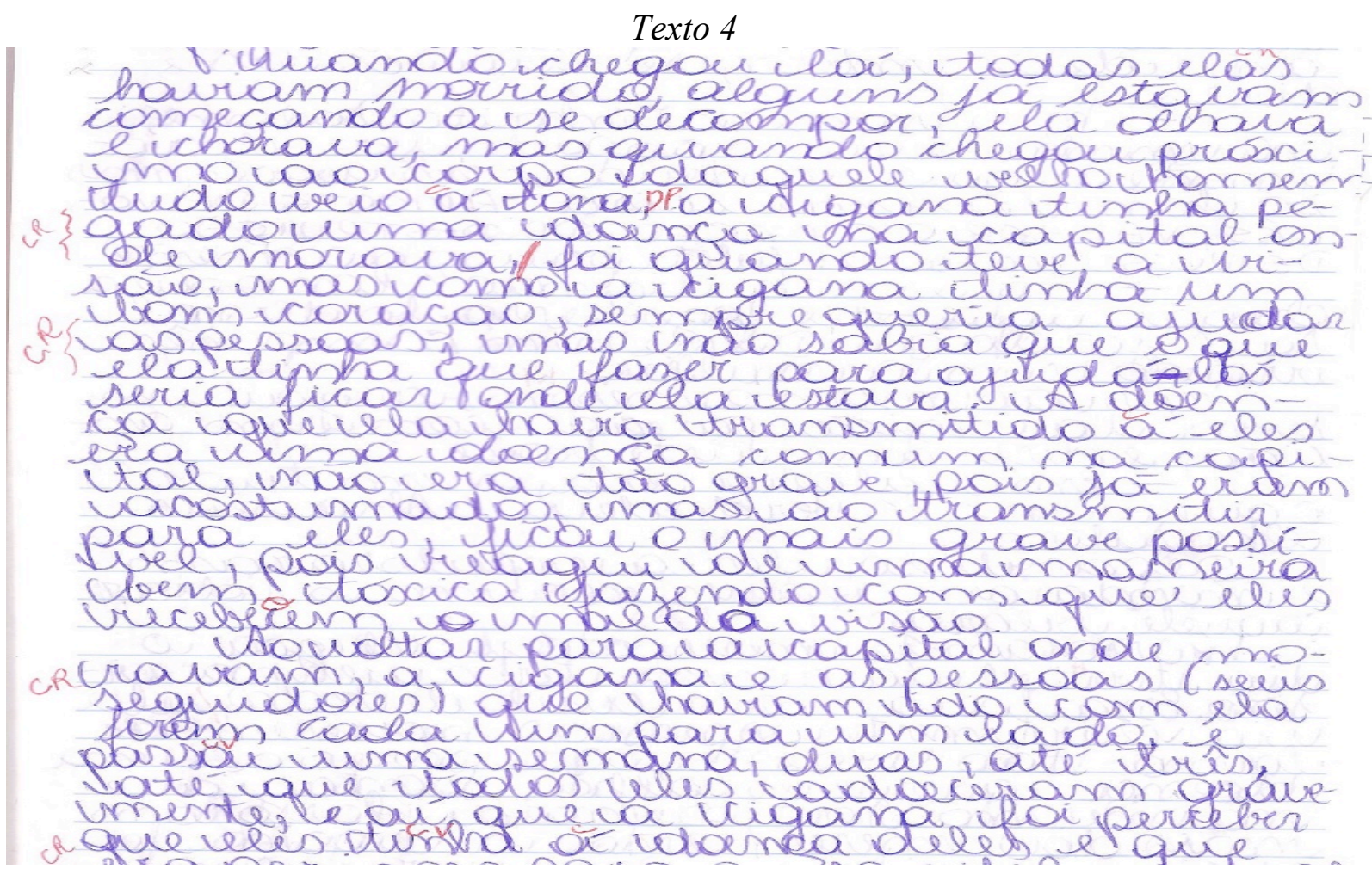

Wuando ichegarom lá, todas elas hauram inovide, volaums ya ustavam come uande wa ve volcoompot, ula collhava e cho-

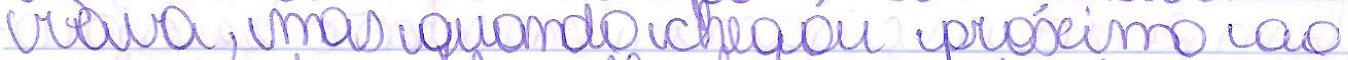
Goypo idaguele uelho homemi dudo veio à Vona, salamé unowa unvito volistante

douilarijo, lla unorava una capital, al seja, denbtur do país, lo virlarefio licava Yora rola capitale, ourlarjo viaulima ilna, ela timka pegado unma idisenca ma capital conde unorava, mas com no já vivtia láichá muito tempo, fá tinka se vacostumado com la colorica, mas unamdo uchegou caté aquele vilaryio,

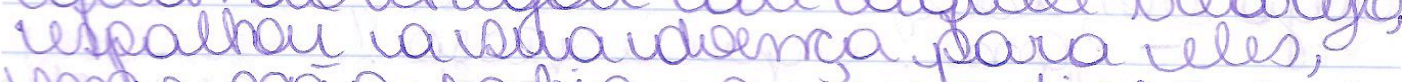
Has não sabia uque veradisso que

O texto 5 ficou bem extenso e períodos muito longos. Não apresentou grandes problemas. Teve uma boa progressão, com temática bem definida. Os problemas que surgiram 
foram em parágrafos, acentuação e pontuação. Na reescrita, ela quase os eliminou, menos nesta passagem; provavelmente, por distração, saltando, inclusive, palavras.

Texto5

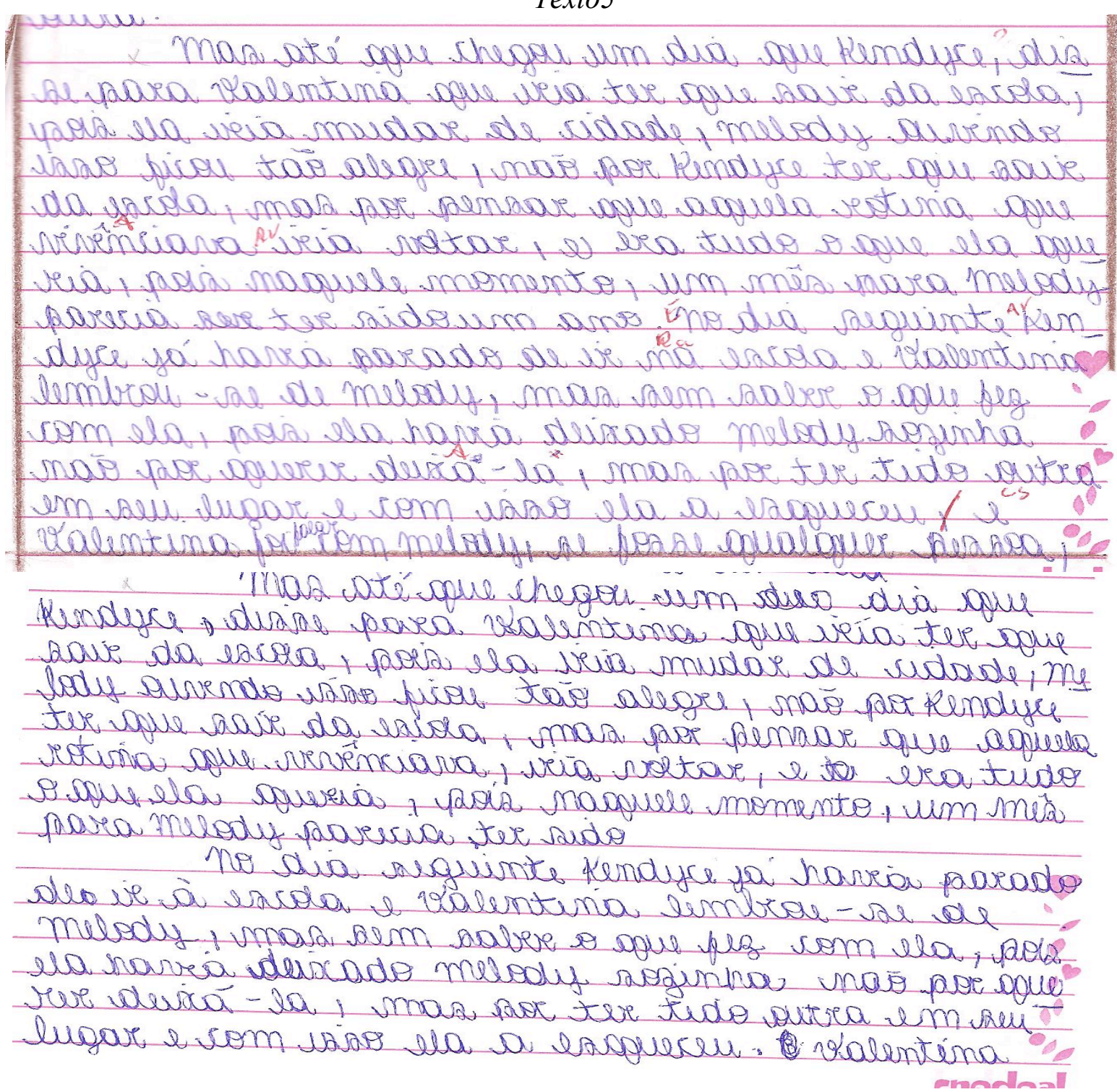

\section{Considerações finais}

Trabalhar a língua através dos textos possibilita ao aluno um domínio linguístico situado, contextualizado, onde ele percebe os recursos linguísticos como constituintes de pensamentos, estratégias discursivas, determinantes de posicionamentos.

A SD é viável para o ensino fundamental, se houver um lento trabalho de suas etapas, com atividades consecutivas. $\mathrm{O}$ espaçamento das etapas acabou comprometendo o resultado. Além disso, houve interferência de outras atividades, promovendo cortes no andamento de algumas fases da sequência, interrompendo a sua realização. 
Percebi também que o aluno necessita de um tempo maior, de uma diversidade de atividades para absorver determinados recursos linguísticos oferecidos pelos textos que servirão de base para suas produções.

Outro ponto que precisa ser revisto são os símbolos que foram utilizados (Ruiz, 2010) para marcar os problemas dos textos. Há necessidade de uma adaptação das referências significativas de cada símbolo, pois os alunos não dominam a terminologia adotada. Sua simplificação direcionaria melhor a percepção dos problemas pelos alunos.

$\mathrm{O}$ ensino da língua orientado pela AL, a partir da produção do aluno, fornece todas as condições necessárias para transformar o domínio linguístico do aluno e, para ela aconteça, não há necessidade de estabelecer uma SD. Basta um estudo consistente com textos focando, detalhadamente, o que se pretende ensinar.

\section{Referências}

BAKHTIN, (Volochinov), M. Marxismo e filosofia da Linguagem. São Paulo. Editora Hucitec, 1995.

BUNZEN, C. ; MNDONÇÃO, M. (Org.). Português no ensino médio e formação do professor. São Paulo. Parábola Editorial, 2006.

GERALDI, J. W. Portos de Passagem. São Paulo. Martins Fontes, 2013. . O texto na sala de aula. São Paulo. Anglo, 2012.

KOCH, I. V. O texto e a construção dos sentidos. 9. ed. São Paulo. Editora Contexto, 2007. . Desvendando os segredos do texto. 5. ed. São Paulo. Editora Cortez, 2006.

QUEIRÓS, B. C. Ciganos. São Paulo. Global Editora, 1982.

RUIZ, E. D. Como corrigir redações na escola: uma proposta textual-interativa. São Paulo. Editora Contexto, 2013.

SCHNEUWLY, B.; DOLZA, J. Gêneros orais e escritos na escola. Tradução de Roxane Rojo e Glaís Sales Cordeiro.. Campinas, SP:Mercado das Letras, 2004. 